\title{
Profile of trauma related mortality at Manipal
}

Singh $\mathbf{B}^{1}$, Palimar $\mathbf{V}^{1}$, Arun $\mathbf{M}^{1}$, Mohanty $\mathbf{M K}^{\mathbf{2}}$

${ }^{1}$ Department of Forensic Medicine, Kasturba Medical College, Manipal, India, ${ }^{2}$ Department of Forensic Medicine, Dr. Pinnamaneni Siddhartha Institute of Medical Science, Chinoutpalli, AP, India

\begin{abstract}
Background: the main objective of the present study is to analyse the pattern of death related to trauma/injuries at Manipal in Udupi district, Karnataka state, India.

Material and methods: Retrospective data (January 2001 to December 2003) were collected from autopsy reports maintained in the department of forensic medicine, and the inquest reports from the police. Out of the total ( $\mathrm{n}=470$ ) autopsies, 344 victims had traumatic fatality. The demographic data, type of trauma, duration of survival, body areas involved was recorded.

Results: 470 autopsies were performed during the period of study. Of these 344 (73\%) were traumatic fatalities. Males were preponderant (71\%). More than half of the victims were between 1-40 years. The youth age of 21-30 years were affected maximum due to all type of trauma except for falls and assault in this area of the country (India). The leading type of trauma was Road Traffic Accident (RTA) (52\%) followed by burn (24\%). Females were predominant with 74\% in trauma due to burns. In majority of cases where the death was reported in the hospital, among them more than $50 \%$ of victims were survived in hospital for more than 24 hours. The victims those expired within 3 hours were in majority from RTA and those who survived for more than 24 hours were in majority from burns. Majority (258) of the victims had head injuries followed by thoracic injuries (169), and abdomen (125). Twenty four percent of the victims died on the spot or before reaching hospital.

Conclusion: In this area of the country the trauma due to RTA is a leading cause of death among the traumatic death followed by burns.
\end{abstract}

Keywords: Trauma, Road Traffic Accident, Death Related Trauma, Burn

Tnjuries and violence pose a major public health and Idevelopment problem world-wide. According to World Health Organisation (WHO) data for 2000, an estimated 5.06 million people die each year as a result of some form of injury, comprising almost $9 \%$ of all deaths ${ }^{1}$.

This equates to almost 14000 injury deaths per day. For each death from trauma there is many more injuries that result in hospitalisation, treatment in emergency departments or treatment by practitioners outside the formal health sectors. Combined data from high-income countries, such as the Netherlands, Sweden and the United States of America, indicate that in these countries for every person killed by injury, approximately 30 times as many people are hospitalised and roughly 300 times as many are treated in hospital emergency rooms and then discharged ${ }^{2}$. Many of the injured will be left with disabling sequelae, and in some cases, permanent ones $^{3}$. When disability resulting from injuries is also taken into consideration, injuries represent an even more significant public health problem, especially in light of the fact that injuries affect mainly young people, that is to say, the economically most productive sector of the population. The magnitude of the problem can be quantified in terms of the number of years lost due to premature death, and the number of years lived with disability (i.e. the burden of disease). Globally trauma currently accounts for $10 \%$ of all disability adjusted life years (DALYs) lost, and this is expected to increase to $20 \%$ by $2020^{4,1}$. In this area, it has been observed that the RTA is one of the leading causes of premature mortality among the traumatic death followed by burns. RTA is preventable event usually taking place as a result of collision of a vehicle/ automobile with a pedestrian, or another vehicle. The inappropriate proportion between the increase in number of vehicles with high-speed

Correspondence

Dr. Bhoopendra Singh,

Associate Professor,

Department of Forensic Medicine \& Toxicology,

Kasturba Medical College,

Manipal, 576104, India

E-mail: drbsingh2003@yahoo.com 
technology and width of the road may be a reason for increasing the RTA cases. In addition to this the other contributing factors like rash and negligent driving, violation of traffic rules, driving under influence of alcohol, and inexperienced drivers without proper driving license could be the reasons/ factors for more RTA related mortality in Karnataka, India.

Despite the undisputed impacts of the injury burden, limited attention has been paid to injury as a public health problem, particularly in low -income countries. There are several reasons for this relative inaction, one of which is the lack of reliable and valid information on injuries that makes the size of the problem invisible to policy makers.

The present study attempts to overcome these lacunae and thereby suggesting to the concerned authorities/ policy makers to initiate measures in order to minimise the mortality related to trauma.

\section{Materials and methods}

Of the 470 autopsies performed on all types of unnatural deaths in the department of Forensic Medicine of Kasturba Medical College, Manipal, Udupi, Karnataka, India between January 2001 to Decenber 2003. Retrospective data were collected from autopsy reports maintained in the department, and the inquest reports from the police. Out of the total number of autopsies, 344 victims were related with traumatic fatality. The demographic data, type of trauma, duration of survival, body areas involved were recorded. While documenting the body area involved, anatomical location was considered and not the clinical prognosis. Under type of trauma, the others include drowning, smothering and electrocution and assaults include firearm, stabbing, and cut-throat injury. Based on survival period, the duration of survival was divided in to four phases: - phase-I from the scene of incidence to arrival of the patients to hospital (Pre-hospital - spot or brought dead), PhaseII from initial assessment in the casualty/emergency department to shifting to ICU/operation theatre $(>3 \mathrm{hrs}$ to $12 \mathrm{hrs}$ ), phase-III from surgical intervention/ ICU to secondary complication ( $>12 \mathrm{hrs}$ to $24 \mathrm{hrs}$ ) and phaseIV from secondary to tertiary complication of trauma ( $>1$ days to 30 days). The data were compiled and analysed by using SPSS-10 software. The results have been presented in the form of figure and tables.

\section{Results}

Over a period of three years, 470 cases were brought by police to conduct medico legal autopsies in the Autopsy Centre of Kasturba Medical College, Manipal. Out of 470 cases $344(73 \%)$ cases had died due to trauma. Of these trauma victims, majority $178(52 \%)$ cases were of Road Traffic Accidents (RTA) followed by burns 81 (24\%) and falls 42 (12\%) (Fig-1).

The males comprised $72 \%$ and females $28 \%$ of total cases. The majority 151 (44\%) men died due to Road Traffic Accidents related trauma and in women majority $60(17 \%)$ died due to burns of total cases. $85 \%$ of Road Traffic Accidents related deaths occurred among men, with women accounting for $15 \%$ only, while in burns related deaths females accounting majority (74\%) (Fig 1).

The majority of the victims were young. The age group of 11-40 years constituted the majority (58\%) of trauma victims followed by age group 41-50 years (15\%) and 51-60 years $(13 \%)$. The youth's age $21-30$ years were most commonly effected due to all type of trauma except for falls and assault (Table-1).

The majority of deaths occurred in the phase-IV-184 $(53 \%)$. The victims those were survived in the hospital for more than 24 hours, of these $68(37 \%)$ were due to burns. Those who survived for less than 24 hours 160 (47\%), of these majorities of deaths occurred in phase-I 83 (24\%), of which 49 (59\%) were due to Road Traffic Accidents and $21(25 \%)$ were due to trauma of others category. Trauma deaths following road traffic accidents predominantly occurred in phase-I $49(28 \%)$ and phaseII $30(17 \%)$. Similarly, the victims of others category of trauma i.e. traumatic asphyxia and assaults, the maximum deaths occurred in phase-I. Trauma victims dying in phase-I were either those who died at scene of incidence or on the way before reaching the hospitals (Table-2).

The Table -3 depicted the involvement of body areas in different trauma cases. In RTA out of 178 cases the involvement of head in 159, followed by thorax and abdomen 50 and 35 cases respectively. In burn's victims, the thorax was involved in majority (79 cases out of 81), followed by abdomen and extremities. In fall's victims, the head was involved in 23, and thorax in 12 . 


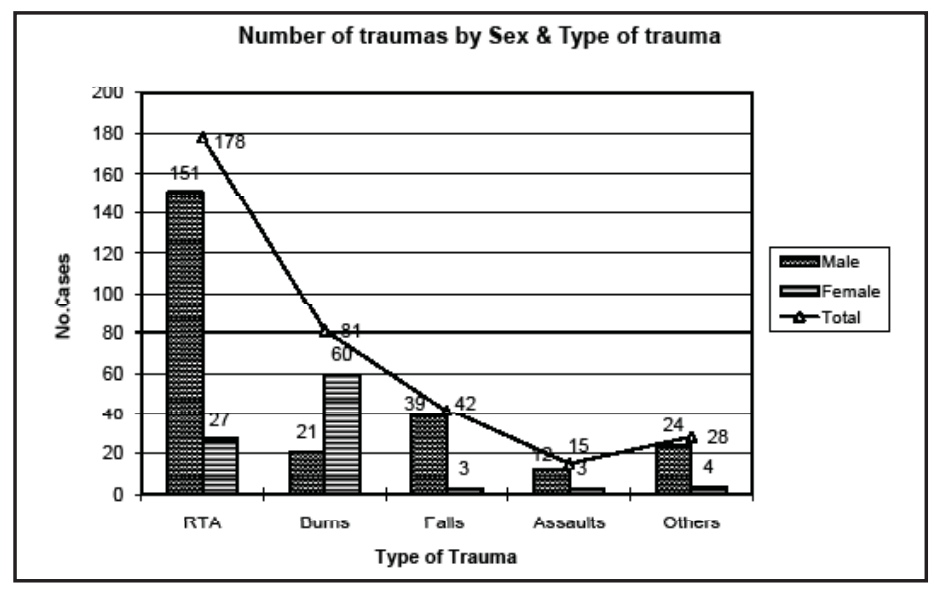

Fig 1: Mechanism of Trauma vis-a-vsi Sex

Table 1: Mechanism of Trauma vis-à-vis age-group

\begin{tabular}{|c|c|c|c|c|c|c|}
\hline \multirow{2}{*}{ Age Groups } & \multicolumn{5}{|c|}{ Mechanism of Trauma } & \multirow{2}{*}{ Total } \\
\hline & Traffic (RTA) & Burns & Falls & Assaults & Others & \\
\hline $0-10$ & $\begin{array}{c}06 \\
3.4 \%\end{array}$ & $\begin{array}{c}04 \\
5.0 \%\end{array}$ & $\begin{array}{c}01 \\
2.4 \%\end{array}$ & 00 & $\begin{array}{c}03 \\
10.7 \%\end{array}$ & $\begin{array}{c}14 \\
3.8 \%\end{array}$ \\
\hline $11-20$ & $\begin{array}{c}28 \\
15.7 \%\end{array}$ & $\begin{array}{c}08 \\
10.0 \%\end{array}$ & $\begin{array}{c}04 \\
9.5 \%\end{array}$ & 00 & $\begin{array}{c}06 \\
21.4 \%\end{array}$ & $\begin{array}{c}46 \\
12.5 \%\end{array}$ \\
\hline $21-30$ & $\begin{array}{c}40 \\
22.5 \%\end{array}$ & $\begin{array}{c}22 \\
27.2 \%\end{array}$ & $\begin{array}{c}10 \\
23.8 \%\end{array}$ & $\begin{array}{c}04 \\
26.7 \%\end{array}$ & $\begin{array}{c}10 \\
35.7 \%\end{array}$ & $\begin{array}{c}96 \\
26.1 \%\end{array}$ \\
\hline $31-40$ & $\begin{array}{c}27 \\
15.2 \%\end{array}$ & $\begin{array}{c}12 \\
15.0 \%\end{array}$ & $\begin{array}{c}20 \\
47.6 \%\end{array}$ & $\begin{array}{c}05 \\
33.3 \%\end{array}$ & $\begin{array}{c}02 \\
7.1 \%\end{array}$ & $\begin{array}{c}69 \\
18.7 \%\end{array}$ \\
\hline $41-50$ & $\begin{array}{c}30 \\
16.5 \%\end{array}$ & $\begin{array}{c}11 \\
13.6 \%\end{array}$ & $\begin{array}{c}07 \\
16.7 \%\end{array}$ & $\begin{array}{c}03 \\
20.0 \%\end{array}$ & $\begin{array}{c}02 \\
7.1 \%\end{array}$ & $\begin{array}{c}60 \\
16.3 \%\end{array}$ \\
\hline $51-60$ & $\begin{array}{c}24 \\
13.5 \%\end{array}$ & $\begin{array}{c}18 \\
22.2 \%\end{array}$ & 00 & $\begin{array}{c}02 \\
13.3 \%\end{array}$ & 00 & $\begin{array}{c}48 \\
13 \%\end{array}$ \\
\hline$>60$ & $\begin{array}{c}23 \\
13 \%\end{array}$ & $\begin{array}{c}06 \\
7.4 \%\end{array}$ & 00 & $\begin{array}{c}01 \\
6.7 \%\end{array}$ & $\begin{array}{c}05 \\
17.9 \%\end{array}$ & $\begin{array}{c}35 \\
9.5 \%\end{array}$ \\
\hline
\end{tabular}

Table 2: Duration of Survival vis-à-vis Mechanism of trauma

\begin{tabular}{|c|c|c|c|c|c|c|}
\hline \multirow{2}{*}{ Time of Survival } & \multicolumn{6}{|c|}{ Type of Trauma } \\
\hline & RTA & Burns & Fall & Assaults & Others & Total \\
\hline $\begin{array}{l}\text { Phase-I } \\
\text { (on spot \& Brought dead) }\end{array}$ & $\begin{array}{c}49 \\
28.2 \%\end{array}$ & 00 & $\begin{array}{c}06 \\
14.3 \%\end{array}$ & $\begin{array}{c}07 \\
46.7 \%\end{array}$ & $\begin{array}{c}21 \\
75.0 \%\end{array}$ & $\begin{array}{c}90 \\
24.4 \%\end{array}$ \\
\hline Phase-II (3.0 - 12 hrs) & $\begin{array}{c}30 \\
17 \%\end{array}$ & $\begin{array}{c}06 \\
1.2 \%\end{array}$ & $\begin{array}{c}06 \\
9.5 \%\end{array}$ & $\begin{array}{c}02 \\
13.3 \%\end{array}$ & $\begin{array}{c}02 \\
7.1 \%\end{array}$ & $\begin{array}{c}41 \\
6.2 \%\end{array}$ \\
\hline Phase-III (12.01- 24hrs) & $\begin{array}{c}29 \\
16 \%\end{array}$ & $\begin{array}{c}07 \\
8.6 \%\end{array}$ & $\begin{array}{l}04 \\
9.6\end{array}$ & 00 & $\begin{array}{c}01 \\
3.6 \%\end{array}$ & $\begin{array}{c}36 \\
9.8 \%\end{array}$ \\
\hline $\begin{array}{l}\text { Phase-IV } \\
(>1 \text { - } 15 \text { Days }) \\
>15 \text { Days to } 30 \text { days }\end{array}$ & $\begin{array}{c}46 \\
25.8 \% \\
24 \\
13 \%\end{array}$ & $\begin{array}{c}44 \\
54.3 \% \\
24 \\
30.0 \%\end{array}$ & $\begin{array}{c}21 \\
50.0 \% \\
05 \\
12.0 \%\end{array}$ & $\begin{array}{c}04 \\
26.7 \% \\
02 \\
13.3 \%\end{array}$ & $\begin{array}{c}03 \\
10.7 \% \\
01 \\
3.6 \%\end{array}$ & $\begin{array}{c}121 \\
32.9 \% \\
80 \\
21.7 \%\end{array}$ \\
\hline Total & 178 & 81 & 42 & 15 & 28 & 344 \\
\hline
\end{tabular}


Table 3: Mechanism of Trauma vis-à-vis Body Areas involved

\begin{tabular}{|l|c|c|c|c|}
\hline Type & Head & Thorax & Abdomen & Extremities \\
\hline RTA & 159 & 50 & 36 & 65 \\
\hline Burns & 67 & 79 & 76 & 55 \\
\hline Fall & 23 & 12 & 07 & 04 \\
\hline Assault & 06 & 02 & 02 & 04 \\
\hline Others & 03 & 26 & 04 & 13 \\
\hline
\end{tabular}

\section{Discussion}

This autopsy study is the first of its kind in the Manipal, and the findings may have considerable research to the care of trauma patients both at pre-hospital and hospital levels. This study is useful in understanding the circumstances of deaths, and thus will be helpful in identifying the factor of importance in the prevention of these deaths.

Injuries and violence pose a major public health development problem world-wide. According to recent estimates of WHO, each year over 5 million people around the world die as a result of an injury ${ }^{1}$. As per NCRB (India) reports in the year 2000 that nearly 5, 00,000 persons were killed in India ${ }^{5}$. The number of trauma victims is not clearly known, since hospitals do not report to a single recording/reporting agency. As per WHO, it is estimated that for every death, 10-20 gets hospitalized and 50-100 receives emergency care, indicating the enormous burden on the resources of the country ${ }^{6}$.

The majority (57\%) of victims were young adults (between 11-40 years), followed by victims between age of 41-60 years (29\%). Only ten percent were aged above 60 years and only 4\% were aged below 10 years. Among these, the age group of 21-30 years was more prominent, followed by age group of 31-40 years. These findings are very similar to the others reported ${ }^{7}$. The youth's age of 21-30 years were maximum affected due to all type of trauma except for victims of falls and assault where maximum from the age group of 31-40 years.

The present study revealed that of the total autopsies $78 \%$ died due to trauma. Road Traffic Accidents were the single most important traumatic cause of death in the overall population, accounting for $52 \%$ of deaths from trauma. This finding is comparable to studies done by Sharma et $\mathrm{al}^{8}(57 \%)$, and Sindhu et $\mathrm{al}^{7}(45 \%)$. The high incidence of road traffic accidents is probably due to multifericity of the vehicles running on the same road, high speed, and to a large extent lack of traffic sense, pedestrians crossing the road at their own will and ignorance of people regarding safety rules. It is also reported in Injury and Alcohol report for WHO that among the injuries, road traffic injuries - falls - burns drowning - poisoning - disasters - agricultural and work place injuries - suicide and violence constitute the major injury causes. Significant urban - rural, socioeconomic differences are noticed across the country. Nearly 85,000 persons were killed in road traffic injuries, while suicides and homicides contributed for 1,20,000 and 40,000 deaths, respectively ${ }^{9}$. Moreover, most of the RTA victims sustained severe cranio-cerebral or multiple injuries. The findings of the present study that $82 \%$ of RTA victims were sustained head injury, which is also supported with the findings of Akang et $\mathrm{al}^{10}(83 \%)$, Menan et $\mathrm{al}^{11}(82 \%)$, Chandra et $\mathrm{al}^{12}(72 \%)$ and $\mathrm{WHO}^{6}$ report. From the above facts, it is clearly indicate that the head is the most vulnerable part of body involved in RTA, which alone accounts for most the fatalities.

Burns is a second (24\%) leading cause of traumatic death and major challenges to the health care provider. Similar incidence was also reported from the study of Sindhu et $\mathrm{al}^{7}(20 \%)$, and Batra $\mathrm{AK}^{13}(23 \%)$. About $52 \%$ of the victims were in the age group of 11-40 years, which are similar to the observation of Batra $\mathrm{AK}^{13}(72 \%)$ from Akola, Singh et al ${ }^{14}$ (67\%) from Chandigarh, Jayaraman et $\mathrm{al}^{15}(59 \%)$ from Madras, and Gupta et al ${ }^{16}$ $(65 \%)$ from Jaipur have also reported higher mortality in young persons. In other countries like Spain ${ }^{17}$ study reported that the majority $61.5 \%$ of victims were over 40 years of age and were males, which are contradicting to the findings of the present study. Of all burn death cases, 74\% were females, The more incidence of burn deaths amongst females was observed throughout the study period and is usually related to compromised working environment in the in-laws house especially for work in kitchen and commonly wear loose fitting synthetic dress materials especially Sarees, which leads to accidental burn trauma or some times dowry disputes, marital disharmony, sexual jealousy etc in manner of suicidal or homicidal deaths. Higher incidences of women burns occurred in India have also been reported by many authors ${ }^{14,16}$. The majority of deaths $(85 \%)$ occurred within a week, signifying that the burns are rapidly fatal. Similarly, Kumar et al ${ }^{18}$ also reported deaths due to burns within a week in $61 \%$, Ragheb et $\mathrm{al}^{19}$ in $58 \%$ victims. Among the all deaths due 
to posttraumatic complications, the septicaemia was the leading cause of death as also reported by Ragheb et $\mathrm{al}^{19}$, Singh et $\mathrm{al}^{14}$.

Falls were third major cause of death in our series. It is similar to findings of Sidhu et al $(11.5 \%)^{7}$ and Singh et $\mathrm{al}^{20}$. Traumatic deaths due to falls are not uncommon. The present study revealed that the majority of victims of falls among the age group of 21-30 years and followed by adult more than 40 years of age. Similar observations were reported by Lalvani et al $1999^{21}$.

Of the deaths associated with trauma $24 \%$ of victims were died within the first three-hours and majority $(79 \%)$ of the victims, who reached hospital and survived for a different interval. Of the deaths due to RTA, only $28 \%$ of victims died on spot or bought dead while majority $(53 \%)$ of victims were survived in the hospital more than $24 \mathrm{hrs}$. This finding of the present study showed a contrast to the common connotation of that most of the victims of RTA die either at accident spot or on the way to the hospital. This could be because of the services of special mobile ambulances to pickup the accident victims from the roadside/ accident site and provide prompt treatment in the hospital. A study was conducted by Chandra et al $1979^{12}$ observed that the spot deaths had markedly declined by introducing the special mobile ambulance services to accident patients. Among the thermal injuries (84\%) of the victims were survived for more than days. A large number of victims died in the hospital. The $34 \%$ of the trauma patients died in the first few days probably due to result of posttraumatic complications. There were considerable numbers (19\%) of patients who survived for more than two weeks and later died as a result of secondary complications like sepsis or multiple organ system failure is predominate as late causes of death similar observation reported by Reber et $\mathrm{al}^{22}$. The findings of this study are contrast to results where the findings showed that the majority of patients died within first hour followed by in days ${ }^{12}$, 23. The dissimilarities in findings of the present study with others could be due to the pre-hospital delays and inappropriate mode of transportation ${ }^{24}$.

The study has documented that injuries to the head are more common in RTA followed by injuries to the thorax and abdomen. This observation calls for the need to strictly implement the wearing of crash helmets approved by ISI, for two-wheeler riders and pillion riders. It is also sthat the driver and the other occupants of four wheelers must mandatory use the seat belts. The pedestrians must also be made to follow the traffic regulations strictly. Burns are the second commonest type of trauma. Domestic accidental burns are more common with females being the major victims ${ }^{25}$.
Traditional wearing attire likes Saries and lack of safety measures in the rural households could be attributed to the accidental catching of fire. Awareness programmes about safe-kitchen is the need of the hour.

\section{Conclusion}

The present study highlights the following features pertaining to the traumatic deaths:

1. Peak incidence of mortality is in the adolescents and young age groups 11-40 years

2. Road Traffic Accidents were the major cause of trauma.

3. Majority of the burns victims were females in childbearing age.

4. Majority of deaths occurred within a week of the incidence.

5. Most of the victims had head injury.

6. Septicaemia was the major cause of deaths due to burn.

\section{References}

1. Penden M, McGee K, Sharma G. The injury chart book: a graphical overview of the global burden of injuries. Geneva: World Health Organization, 2002.

2. Injury Pyramid. Geneva: World Health Organization; 2001.

3. Krug EG, Sharma GK, Lozano R. The global burden of injuries. American Journal of Public Health. 2000, 90: 523-6.

4. Muray CJL, Lopez AD. Alternative projections of mortality and disability by cause 1990-2020: Global Burden of disease Study. Lancet. 1997, 349: 1498-504.

5. National Crime Record Bureau (India), 2000.

6. World Health Organization - Strategic Plan for Injury prevention and control in South East Asia, April 2002.

7. Sidhu DS, Sodi GS, Banerjee AK. Mortality profile in trauma victims. J Indian Med Assoc.1993 Jan; 91(1): 16-8.

8. Sharma BR, Gupta M, Bangar S, Singh VP. Forensic considerations of missed diagnoses in trauma deaths. Journal of Forensic and Legal Medicine 2007;14: 195-202.

9. Benegal V, Gururaj G, Murthy Pratima, Taly Arun B, Shashi Kiran, Chandrashekar R, Chandrashekar H. Injury and Alcohol, Report for the World Health Organization, 2003.

10. Akang EEU, Kuti MAO, Osunkoya AO et al. Pattern of fatal haed injuries in Ibadan-a 10 year review. Med Sci Law 2002; 42 (2): 160-6. 
11. Menon A, Pai VK, Rajeev A. Pattern of fatal head injuries due to vehicular accidents in Mangalore. Journal of Forensic and Legal Medicine.. 2008;15: 75-7.

12. Chandra J, Dogra TD, Dikshit PC. Pattern of Cranio-intracranial injuries in fatal vehicular accidents in Delhi, 1966-76. Med Sci Law. 1979, 19 (3): 186-94.

13. Batra AK. Burn mortality: recent trends and sociocultural determinants in rural India. Burns. 2003 May; 29(3):270-5.

14. Singh D, Singh A, Sharma AK, Sodhi L. Burn mortality in Chandigarh zone: 25 years autopsy experience from a tertiary care hospital of India. Burns. 1998 Mar; 24(2): 150-6.

15. Jayaraman V, Ramakrishnan KM, Davies MR. Burns in Madras, India: an analysis of 1368 patients in 1 year. Burns. 1993 Aug; 19(4): 33944.

16. Gupta M, Gupta OK, Yaduvanshi RK, Upadhyaya J. Burn epidemiology: the Pink City scene. Burns. 1993 Feb; 19(1):47-51.

17. Reig A, Tejerina C, Baena P, Mirabet V. Massive burns: a study of epidemiology and mortality. Burns. 1994 Feb;20(1):51-4.

18. Kumar V, Mohanty MK, Kanth S. Fatal burns in Manipal area: a 10-year study. J Forensic Leg Med. 2007 Jan;14(1):3-6.
19. Ragheb SA, Qaryoute S, EI-Muhtaseb H. Mortality of burn injuries in Jordan. Burns 1984:10:439-43.

20. Singh VP, Aggarwal OP, Tuli H. A postmoretm study of fatal injuries in Govt Medical College, Rajendra Hospital Patiala. JFMT 2004; 21 (1): 47-50.

21. Lalwani S, Agnihotri AK, Talreja A, Murty OP. Pattern of Injuries in fatal falls from height- A retrospective review. J Forensic Medicine \& Toxicology. 1999; 16(2): 38-46.

22. Reber JU, Schmied B, Seiler CA, Baer HU, Patel AG, Bachler MW. Missed diaphragmatic injuries and their long term sequelae. J. Trauma, Injury Infect Crit. Care. 1998; 44(1): 183-6.

23. Ekere AU, Yellowe BE, Umune S. Mortality patterns in the accident and emergency department of an urban hospital in Nigeria. Niger J Clin Pract. 2005 Jun;8(9): 14-8.

24. Siddiqui AA, Zafar H, Bashir SH. An audit of head trauma care and mortality. J Coll Physicians Surg Pak. 2004 Mar; 14(3): 173-7.

25. Manoj K Mohnty, MArun, Francis NP Monteiro, Vikram Palimar. Self-inflicted Burns Fatalities in Manipal, India. Med. Sci Law 2005; 45 (2): 27-30. 